becomes standard practice. This study demonstrates a need for consensus among psychiatrists on how these patients should be managed. At present this appears to depend very much upon to whom they are referred, and many of us do not appear to be practising evidence-based medicine.

\section{Acknowledgements}

The costs of this survey were met by Dista Psychiatric Education Services. We would like to thank them and all the Scottish psychiatrists who took the time to respond to our survey.

\section{References}

ANGST, J. (1992) How recurrent and predictable is depressive illness? In Long Term Treatment of Depression (ed. S. Montgomery). pp 1-13. Chichester: John Wiley.

AYD, F. J. (1984) Long term treatment of chronic depression: 15 year experience with Doxepin $\mathrm{HCl}$. Journal of Clinical Psychiatry, 45. 39-46.
Frank, E., KuPfer, D. J., PEREl, J. M., et al (1993) Comparison of full dose versus half dose pharmacotherapy in the maintenance treatment of recurrent depression. Joumal of Affective Disorders. 27. 139-145.

KUPFER, D. J. (1993) Management of recurrent depression Journal of Clinical Psychiatry, 54 (suppl.), 29-33: 34-35.

-. Frank, E., PEREL, J. M., et al (1992) Flve year outcome for maintenance theraples in recurrent depression. Archives of General Psychiatry, 49, 769-773.

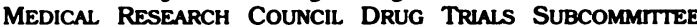
(1981) Continuation therapy with lithium and amitryptiline in unipolar depressive illness: a controlled clinical trial. Psychological Medicine, 11, 409.

MONTGOMERY. S. A. (1996) Efficacy in long term treatment of depression. Joumal of Clinical Psychiatry, 67 (suppl. 2). 24-30.

*Graham A. Jackson, Senior Registrar in Old Age Psychiatry, Hairmyres Hospital, Eaglesham Road, East Kilbride, Lanarkshire; Ishbel Maciver, Senior Registrar in Psychiatry, Douglas Inch Centre, 3 Woodside Terrace, Glasgow

*Correspondence

\title{
Psychopathy in Scotland
}

\author{
Martin Humphreys
}

Alms and method The aim was to examine why the legal category of psychopathic disorder does not appear in the Mental Health (Scotland) Act 1984 and to review selected literature relating to differences between prison and special hospital populations in Scotland from those elsewhere.

Results There is now some emerging evidence to suggest that the legislation north of the border might reflect the notion that there may be fewer people with psychopathic disorders in Scotland.

Clinical implications With devolution and the advent of a Scottish Parliament the Mental Health (Scotland) Act 1984 is likely to be reviewed. At that time it would be inappropriate to consider including 'psychopathic disorder' but some alternative to the current rather narrow definition of 'mental disorder' may be required.

There is still much debate over the possible need for reform of current mental health legislation. In considering this the status of the legal category of psychopathic disorder is almost always raised.
Reference has frequently been made to the fact that the term does not appear in the Scottish legislation. Are patients who would receive care and treatment under the 1983 Act being denied that right in Scotland?

Part I of the Mental Health Act 1983 defines the legal category of "psychopathic disorder" as

"a persistent disorder or disability of mind (whether or not including significant impairment of intelligence) which results in abnormally aggressive or seriously irresponsible conduct on the part of the person concerned".

There is, strictly speaking, no equivalent in the Mental Health (Scotland) Act 1984. What it does describe is a mental disorder which "is a persistent one manifested only by abnormally aggressive or seriously irresponsible conduct". The term "mental disorder" however, is previously defined as "mental illness or mental handicap however caused or manifested". It is therefore difficult to imagine what sort of clinical condition might fulfil all the necessary requirements of the 
Scottish legislation. Modern classificatory systems fail to define an adult form of mental illness or disability as such, whose only signs or symptoms take the form of aggression or irresponsible behaviour. This difference is reflected in the relatively small number of patients detained in these terms in Scotland when compared to those in the mental illness, mental impairment or severe mental impairment categories. The exact reasons for this though, have been unclear. Perhaps psychiatrists do not detain patients on the grounds described for purely legal reasons. There may, however, be other considerations. Interestingly a significant proportion of those training in psychiatry in Scotland believe incorrectly that the presence of a personality disorder or "psychopathy" in itself specifically precludes detention under the Mental Health (Scotland) Act 1984 (Humphreys, 1997).

Clinical considerations obviously play a significant part too, and the treatability criteria are identical to those found in the 1983 Act in relation to psychopathic disorder. For courts and psychiatrists alike in Scotland the issue becomes one of attempting to make the clinical picture fit within the legal framework in order to be able to detain patients in this category. It has been suggested that the apparent unwillingness in Scotland to offer treatment to, or formally detain individuals who might otherwise be included in this group, even in conditions of special security, has its roots in the history of the State Hospital and the circumstances surrounding the escape of two patients in November 1976 (Scottish Home and Health Department, 1977; Coid, 1987). However, powerful and persuasive arguments have been advanced against the compulsory detention of people with psychopathic disorders in special hospitals and indeed elsewhere, and not only in Scotland (Chiswick, 1987. 1992: Grounds, 1987). Other evidence suggests that attitudes to the treatment of people with psychopathic disorders vary widely anyway (Cope, 1993).

In England and Wales relatively few patients are detained on the grounds of psychopathic disorder in local psychiatric facilities or even within regional secure units, although more than one in four of those in maximum security psychiatric care do fall into that category (Taylor et al, 1991). In the equivalent facility at the State Hospital, Carstairs, very few patients are detained in terms of the Scottish 'equivalent' and only $5 \%$ have a primary diagnosis of antisocial personality disorder (Thomson et al, 1997). In this context it is important to remember of course that the term psychopathy, used in a diagnostic sense, does not mean the same as antisocial personality disorder and that each of these is different again from the legal category of psychopathic disorder into which a whole range of diagnostic groups may be subsumed (Blackburn et al, 1990; Coid, 1992).

So people with psychopathic disorders are not described in the Scottish mental health legislation nor are they enmeshed in the hospital system, at least not in any great numbers. The popular notion has been that those individuals who might have received a psychiatric disposal on the grounds of psychopathic disorder in England and Wales coming before courts in Scotland were dealt with by way of the criminal justice system and that as a result many of them languish, untreated, in prison. In a recent study of the prevalence of mental disorders among the remand population in Scotland no measure of personality disorder was included among the instruments used, primarily in recognition of the difficulties associated with accurate diagnosis of this group in prisons, but also on the assumption that they would be included in other groups such as those with alcohol or drug dependence (Davidson et al, 1995). However, Cooke (1994) identified only $3 \%$ of a sample of sentenced prisoners in Scotland who fulfilled criteria for psychopathy using the conventional cut-off point on the Psychopathy Checklist (Hare, 1980) compared to a figure of $23 \%$ among North American prisoners using the same instrument and parameters (Cooke, 1996). The extent to which these cross-cultural findings are reliable is still not yet entirely clear, although further studies are currently in progress. At present, however, they would seem to represent a real variation in prevalence between these two prison populations (Cooke, 1997b).

Social influences of all sorts contribute to the multi-factorial origins of personality disorder. Cross-cultural differences lend support to the argument in favour of the existence of the discrete entity of psychopathy rather than the converse (Cooke, 1996). What does now seem likely is that among the prison population there are real differences in the numbers of people with psychopathic disorders in North American penal institutions when compared to those in Scotland (Cooke, 1997b). This could also be true of England and Wales.

So perhaps there could be fewer people diagnosed with psychopathic disorder in Scotland than elsewhere. There is nothing to suggest that there are a greater number of individuals with personality disorders in the community at large and it could be that even those who originate there may move away (Cooke, $1997 a$ ). In which case rather than being purely a matter of psychiatric practice not to detain and treat these people in hospital in Scotland, something which seems to have been a reason for criticism in the past, there may genuinely be less of them. 


\section{References}

Blackburn, R., Crelun, M. C., Morgan, E. M., et al (1990) Prevalence of personality disorder in a special hospital population. Journal of Forensic Psychiatry. 1, 43-52.

CHISwick. D. (1987) Managing psychopathic offenders: a problem that will not go away. British Medical Journal. 285. 159-160.

- (1992) Compulsory treatment of patients with psychopathic disorder: an abnormally aggressive or seriously irresponsible exercise? Criminal Behaviour and Mental Health, 2. 106-113.

CoID. J. (1987) Managing psychopathic offenders. British Medical Journal, 296, 606.

- (1992) DSM-III diagnosis in criminal psychopaths: a way forward. Criminal Behaviour and Mental Health, 2. 78-79.

COOKE. D. J. (1994) Psychological Disturbance in the Scottish Prison System: Prevalence. Precipitants and Policy. Edinburgh: Scottish Prison Service.

- (1996) Psychopathic personality in different cultures: What do we know? What do we need to find out? Journal of Personality Disorders, 10, 23-40.

- (1997a) Psychopaths: oversexed, overplayed, but not over here? Criminal Behaviour and Mental Health. 7. 3-11.

- (1997b) Cross-cultural aspects of psychopathic personality disorder. In Psychopathy. Theory. Research and Implications for Society (eds D. J. Cooke. A. Forth \& R. D. Hare). Dordrecht: Kluwer.

COPE. R. V. (1993) A survey of forensic psychiatrists' views on psychopathic disorder. Joumal of Forensic Psychiatry, 4, 215-236.
Davidson. M., Humphreys, M. S.. Johnstone. E. C., et al (1995) Prevalence of psychiatric morbidity among remand prisoners in Scotland. British Journal of Psychiatry. 167, 545-548.

GROUNDS, A. T. (1987) Detention of 'psychopathic disorder' patients in special hospitals. Critical issues. British Journal of Psychiatry. 161, 474-478.

HARE, R. D. (1980) A research scale for assessment of psychopathy in criminal populations. Personality and Individual Differences, 1. 111-119.

HUMPHREYS, M. S. (1997) A national survey of nonconsultant grade psychiatrists' knowledge of current mental health legislation in Scotland. Psychiatric Bulletin, 21, 631-635.

ScotTish Home and Health Department (1977) State Hospital, Carstairs. Report of Public Local Inquiry into Circumstances Surrounding the Escape of Two Patients on 30 November 1976 and into Securty and Other Arrangements at the Hospital. Edinburgh: HMSO.

TAYLOR, P. J., BUTWELL. M., DACEY, R., et al (1991) Within Maximum Security Hospitals: A Survey of Need. London: Special Hospitals Authority.

THOMSON, L. J.. BogUE. J. P.. HuMPHREYS, M. S., et al (1997) The State Hospital survey: the circumstances of patients detained in conditions of special security in Scotland. Joumal of Forensic Psychiatry. 8. 263-284.

Martin S. Humphreys. Senior Lecturer in Forensic Psychiatry, Reaside Clinic, Birmingham Great Park, Rubery. Birmingham B45 9BE

\title{
Therapeutic community provision at regional and district levels
}

\author{
Steffan Davies, Penelope Campling and Kerry Ryan
}

\begin{abstract}
Aims and method The aim of the study was to investigate changes in service utilisation following therapeutic community treatment for patients with severe personality disorder. The study examined service usage, in the form of acute psychiatric admissions, of a series of 52 admissions to a residential therapeutic community in the three years before and year after admission.

Results There was a reduction in the mean duration of acute psychiatric admissions after treatment, this was greater for extra-contractual referral patients than local district patients.

Clinical implications This study replicates results from previous studies. It also suggests that more accessible local services may be able to intervene earlier in patients' psychiatric careers preventing heavy use of acute services. We argue for greater provision of
\end{abstract}

therapeutic community treatment for severe personality disorder.

There has been much interest in recent years in the treatment of personality disorder in therapeutic communities. Recent research gives some support for the efficacy (Dolan \& Coid, 1993) and cost-effectiveness (Chiesa et al, 1996, Dolan et al, 1996) of this form of treatment, although no controlled trials exist for practical, ethical and financial reasons (for a fuller discussion see Lees, 1999). Much of the published research has come from the Henderson and the Cassel Hospitals which offer supra-regional services and are largely funded by extra-contractual referrals (ECRs) (Dolan \& Norton, 1992). The patients 